\title{
REFORMAS EDUCATIVAS: ESPEJISMOS DE INNOVACIÓN
}

\author{
Mario César Zaccagnini \\ Investigador del Grupo G.I.S.E.A. (Universidad Nacional de Mar del Plata) \\ María Dolores Jolis (Asesora)
}

\section{INTRODUCCIÓN}

Un punto central para comprender la complejidad de la problemática de la innovación educativa, es la ineludible e imprescindible referencia acerca del impacto que los nuevos lineamientos de la política educativa han introducido en la educación, instaurados a partir de las reformas educativas ejecutadas en la década de los 90, como parte del programa del modelo económico neoliberal que domina a toda la región latinoamericana desde fines de los años 80.

En principio ¿qué es una reforma educativa? Genéricamente, en educación se habla de reformas cuando se ve la necesidad de instrumentar un cambio de organización estructural del sistema; cuando se cambia el diseño curricular y los consecuentes planes de estudio; cuando se pretende modernizar al sistema en su conjunto, imprimiéndole una dinámica más ágil y efectiva al funcionamiento institucional, al descentralizar la burocracia central; cuando se pretende elevar la calidad general de la enseñanza, en aras de mejorar el rendimiento académico de los alumnos y disminuir el fracaso escolar; cuando se pretende adecuar y ajustar la formación educativa a las demandas del mercado laboral; cuando se quiere introducir cambios en los estilos pedagógicos de los docentes; cuando se busca la transformar las culturas institucionales de las escuelas; cuando se busca aggiornar los criterios de organización y gestión institucional de las escuelas, etc.

Bajo un discurso optimista, pareciera que la sola enunciación de los principios transformadores y sus lógicas consecuencias benéficas para el funcionamiento del sistema, bastará para crear por sí solo, las condiciones transformadoras. En efecto, se suelen agitar con cierto fervor declaraciones de principios con las que es fácil estar de acuerdo, estimulando el consenso de los actores educativos a partir de «poner en el tapete» ciertos ideales universales (Gimeno Sacristán, 1999).

Las reformas parecen terminar constituyéndose en huracanes cíclicos, dirigidos a introducir los cambios pretendidos en el funcionamiento del sistema, que observan escasos o muy fugaces efectos, ya que crean una ilusión de cambio pero producen pocas transformaciones reales y bastante desilusión en los actores. No pocas veces se dice que en realidad las reformas se asemejan a un movimiento "gatopardista»: se cambia para que todo siga igual. Uno de los problemas centrales de las reformas es su miopía para abordar ecosistémicamente el dimensionamiento complejo del sistema educativo, como se verá en el siguiente análisis.

Para entender el actual proceso de reforma educativa en la Argentina y en toda la región iberoamericana, es imprescindible describir y analizar el escenario sociopolítico que le confiere sentido. En 
el caso particular de Argentina, se plantea que «de la misma manera en que el proyecto sociopolítico de la Generación del 80 concibió a la educación bajo el paraguas de una pedagogía hegemónica fundante, consecuente con el proyecto político conservador de la élite oligárquica dominante de la época; la actual reforma educativa parecería transitar por andariveles semejantes", es decir, el hecho de redireccionar nuevamente a la educación como uno de los espacios privilegiados para la inculcación del ideario representado por el modelo único de sociedad global, que el proyecto neoliberal viene implementando con relativo éxito. No obstante, como se verá, ambos proyectos son diferentes en lo que atañe al papel del Estado en cada uno.

\section{CONTEXTO SOCIOHISTÓRICO DE LA REFORMAS}

En la Argentina, agotado el modelo de sustitución de importaciones, cuya crisis termina con el proceso hiperinflacionario de 1989 y la consecuente crisis política que termina precipitadamente con el primer gobierno democrático luego de la última dictadura, el gobierno elegido para el segundo período impulsa un acuerdo social destinado a contener la espiral inflacionaria y la consecuente grave crisis económica desatada. Para ello, bajo la supervisión y el monitoreo de los organismos internacionales ya señalados, se aplican planes económicos de claro corte monetarista y propuestas concretas para la reformulación de la función del Estado. Así, se instaura un discurso donde la estabilidad económica cobro un papel fundamental como condición imprescindible para el reordenamiento socioeconómico nacional y se adereza dicha política con fuertes críticas al papel del Estado-empresario-asistencial del modelo inaugurado por el peronismo en los años 40: se puso especial énfasis en el discurso que allanó el proceso privatizador de los años 90, la dramatización sobre las pérdidas que generaban algunas empresas estatales de servicios públicos y a atacar al «intervencionismo paternalista» del Estado, etc.

De esta forma, se justificó el imbricamiento y la ejecución de la política, como visos de cruzada, que permitió el desguace del Estado, con todas las secuelas que la mayor parte de los argentinos conocemos. El viejo Estado nacional fue mostrado en su toda su magnitud como una estructura orgánica obsoleta frente a los desafíos de la «nueva sociedad global» explicitada en el discurso neoliberal, al cual se le achaca la responsabilidad de todos los males que aquejaban al país. Dos cuestiones se atacaron con la reforma del viejo Estado asistencial: por un lado el sobredimensionamiento de la estructura burocrática, es decir, el exceso de funcionarios y empleados públicos correlacionado con la prestación de servicios ineficientes. Por el otro lado, se atacó el papel intervencionista del Estado, en cuanto a su labor planificadora y reguladora (Braslavsky y Cosse, 1997).

Así es como irrumpe en la escena social el remedio a todos los males que desembocaron en la crisis terminal de la hiperinflación de 1989: la economía libre de mercado, la cual es enaltecida a la jerarquía de dogma, postulando que con ella nuestra sociedad lograría la forma más equitativa de distribución de los bienes producidos socialmente. La economía popular de mercado, como eufemísticamente la llamó el gobierno peronista que asumió el poder en 1989, responde a la lógica del proyecto del capitalismo hegemónico puesto en marcha por la denominada tercera revolución industrial (Gentili, 1998). 
La piedra angular del proyecto es la transformación del papel del Estado, tanto en nuestro país como en el resto de los países latinoamericanos. En la línea de las críticas que los apóstatas del neoliberalismo hacen al papel del Estado, las políticas instrumentadas para su profunda transformación reviven las viejas concepciones sostenidas por la ideología liberal-conservadora propia del ideario liberal decimonónico (Bianchetti, 1999).

La política de privatización de las empresas públicas fue el primer gran mecanismo de transferencia de las responsabilidades del área de los servicios públicos del otrora Estado benefactor, hacia el sector privado. Esta política redundó en una profunda transformación de relaciones sociales, en el sentido de constituirse en la arbitración de un nuevo contrato social. Entre otras cosas, se introdujo como baluarte funcional del ideario neo-liberal, el concepto de descentralización, asociado a la lógica de que toda sociedad liberal, sustentada políticamente bajo el paraguas de la democrático, debe dejar librado a la sana competencia del mercado la oferta de bienes y servicios; toda centralización de la producción de estos por parte del Estado constituye una centralización altamente perjudicial.

Sin embargo, la mentada descentralización sólo se circunscribió a la esfera del gasto público, en el sentido de que el Estado nacional transfirió a la esfera de las provincias y los municipios servicios como la patente de la educación, pero adjudicándose la potestad de centralizar la asignación de recursos como créditos de acuerdo a las condiciones impuestas por los bancos y organismos otorgantes de los mismos.

Como lo demuestra la realidad cotidiana, la tercera revolución industrial, traducida en términos del modelo neoliberal-conservador, no ha redundado los beneficios prometidos por sus entusiastas voceros, salvo para una minoría histórica, cada vez más reducida y cada vez más rica; en los conceptos de Gentili (1994, p. 129) disponemos del siguiente cuadro de situación:

Más allá de las promesas liberadoras que acera de la tecnología y e1 conocimiento científico tecnológico formulan los discursos dominantes, el período que se abre a partir de la crisis del régimen de acumulación taylorista-fordista evidencia, por lo menos, la existencia cinco cuestiones fundamentales:

1. Un brutal proceso de concentración económica (en sentido de una impresionante concentración monopólica en materia productiva a partir de la hegemonía que poseen, en los mercados, los grupos económicos nacionales y trasnacionales de tipo integrado y/o diversificado).

2. Un doble proceso de globalización y fragmentación regional a nivel de la economía-mundo. Tal proceso simultáneo va definiendo una estructura productiva mundial imposible de ser asociada a la propia fisonomía geográfica de los Estados-Nación.

3. La reestructuración de los mercados, lejos de suponer un conjunto de procesos orientados a la descentralización de las decisiones y del poder, significa su creciente y progresiva centralización y concentración. Esto es, la nueva fisonomía geográfica del capitalismo a escala mundial no cuestiona -ni fragmenta- la naturaleza centralizada del poder, sino que más bien lo profundiza.

4. Asociado a los ítems anteriores, la tercera revolución industrial significa la cristalización de un profundo proceso de polarización, dualización y marginamiento social de las mayorías. Lo característico de ese proceso en la nueva revolución tecnológica es que los patrones de diferenciación involucran a nuevos sectores sociales definiendo una fisonomía de "ganadores» y «perdedores» difícil de ser aprehendida con las matrices analíticas clásicas. 
En este sentido, repasando el ideario liberal, «aggiornado» bajo la denominación de neoliberalismo, constituye la manifestación más acabada de una perspectiva social bajo el imperio de principios economicistas radicales, fundamentado bajo presupuestos filosóficos y políticos y que sustentan todos los procesos de transformación que se vienen desarrollando en los países de la región.

En el marco del oprobio del endeudamiento externo que los mismos vienen soportando desde las postrimerías de la década de los 70 y principio de los 80 y, liquidada la resistencia que determinadas fuerzas sociales oponían al proyecto liberal-conservador mediante la sangrienta represión llevada a cabo por los gobiernos de facto responsables de dicho endeudamiento, se pone en marcha la instauración y consolidación de un nuevo orden internacional, a partir de las necesidades del proceso de desarrollo capitalista de los países desarrollados.

Organismos internacionales como el FMl y el Banco Mundial cobran un especial protagonismo para constituirse en la voz cantante del modelo; una pléyade de técnicos y funcionarios, bajan las denominadas «recomendaciones» a los gobiernos de los reinaugurados procesos democráticos en buena parte de los países que, como la Argentina, fueron interrumpidos en los años 70. Recomendaciones que se tradujeron en programas aplicados con el propósito de adecuar a la configuración del mapa social al nuevo modelo societal, propugnado por el ideal universalista del ideario neoliberal. Muy conocido es que, dicho modelo, se traduce en un recetario universal instrumentado a todos los países por igual, sin reconocer las particularidades regionales de cada uno de ellos, como bien lo plantea Bianchetti (1999, p. 3 ):

En los hechos esto se expresa a través de estrategias políticas que impulsan la adecuación de diferentes realidades histórico-sociales a esquemas interpretativos elaborados, en muchos casos, con desconocimiento o indiferencia fente a heterogeneidad y las particularidades de las sociedades en las cuales se ejecutan. Una de las razones por las cuales estos organismos actúan de esa manera, está en relación con las nuevas funciones que cumplen como custodios y garantes de las inversiones del capital financiero internacional, siendo en definitiva este último el que determina las condiciones de "confiabilidad» que deben existir en los países para recibir sus inversiones.

Siguiendo con el análisis de Bianchetti, el proyecto del neoliberalismo no es sólo un proyecto económico sino que implica un marco filosófico y la configuración de un modelo social consecuente, el cual presupone la instancia de un cierto tipo de relaciones sociales que se constituyen como resultado de las interacciones de individuos motivados a partir de una determinada escala de valores. El proyecto social neoliberal simplemente pone el acento en la dimensión económica del ideario capitalista como organizador de las relaciones sociales imperantes. Recurriendo a las palabras de Bianchetti (1999, p. 10)

La propuesta social del neoliberalismo, basada en la consideración de que el ámbito de lo económico organiza y disciplina las relaciones sociales, exalta los valores que se expresan en el mecanismo de la oferta-demanda, fundada en la especulación costo-beneficio como principios universales que rigen las acciones de los hombres y de las sociedades. Es imprescindible entender, que estos procesos de transformación llevados adelante en países como el nuestro, obedecen a la lógica propia de la configuración geopolítica histórica del capitalismo y de sus necesarios reajustes frente a las vicisitudes que le deparan las cíclicas crisis que lo afectan. La clásica división del mapa mundial entre países desarrollados y países en vías en desarrollo, cobra nueva vigencia bajo el eufemismo acuñado por los apóstoles del nuevo orden mundial como economías desarrolladas y economías emergentes.

La revolución de la información facilita la consolidación de un proceso de relaciones económicas a escala mundial, conocido como globalización económica. Por lo pronto, la lógica del capitalismo global requiere que los nuevos poderes económicos aseguren las tasas de rentabilidad de sus inversiones para lo cual se hace imprescindible que los países destinatarios de las mismas observen condiciones político- 
institucionales-sociales y culturales adecuadas a fin de ofrecerles un alto grado de previsibilidad por la continuidad de reglas de juego.

Dos vías son necesarias para que ello sea posible: una, la implementación de las denominadas políticas de ajuste, que permitieron en su primera etapa detener los procesos inflacionarios que devastaron las economías de la región, y como consecuencia, reordenar el papel del Estado, reasignándole la doble tarea de crear las mejores condiciones económico-sociales para el alcanzar las metas previstas, identificadas en las recomendaciones del FMI y demás organismos afectados a la supervisión y monitoreo del endeudamiento externo de los países de la región: privatización de los activos públicos, disciplinamiento laboral mediante la llamada flexibilización laboral, achicamiento del gasto social, reordenamiento del sector financiero, privatización del sistema de seguridad social, políticas de reforma educativa, políticas de desregulación de tarifas y aranceles, etc. La otra vía, pensada para el mediano y el largo plazo, consiste en construir una base de consenso social que le confiera legalidad al nuevo orden social que se configura a partir de la instrumentación de los programas mencionados.

En el caso de la Argentina, su sociedad carece de la necesaria base cultural para la instrumentación de un modelo de económico de libre mercado; de ahí que este «nuevo orden mundial» requiere, para la instrumentación y consolidación, de un proceso de generalización de un corpus cultural constituido por los valores económicos y sociales del ideario neoliberal, facilitando así la génesis de una actitud social consecuente con dicho modelo. Esta cultura es la base de la denominada globalización, cuyo objetivo máximo es la integración homogénea de las sociedades que haga posible las relaciones económicas sobre bases únicas y universales. En definitiva, este proceso de difusión cultural es uno de los motores que contribuyen a la configuración de la base consensual legitimadora del modelo.

Esta base de consenso social se torna como imperiosa para el proyecto capitalista hegemónico, por lo cual, no basta la revolución en plano económico sino que hace una profunda transformación en plano cultural que facilite la difusión y la consolidación de valores consecuentes con el ideario neoliberal. La construcción del «sentido común» del ciudadano promedio es fundamental para legitimar la nueva cosmovisión social, que por ende legitima las reglas del juego en el plano económico: la acumulación sostenida de bienes bajo el imperio un nuevo contrato entre Estado, capital y trabajo.

La Argentina, como país periférico, se inserta en un contexto mundial dominado por un reducido número de países, con Estados Unidos a la cabeza, que ostentan la potestad de determinar cuales son las políticas más apropiadas a seguir, bajo el constante chantaje que el endeudamiento externo impone. De ahí que frente a las lógicas resistencias que se le presentan a estas fuerzas del «mercado», se imponga la ineludible necesidad de construir consensos necesarios. Como lo señala Bianchetti (1999, p. 5):

La construcción de una «ideología global», sustentada en un modelo único de sociedad e incorporada como filosofía social en cada una de las sociedades, es el fin último del sistema capitalista y representaría, para la burguesía, un triunfo fundamental sobre otros modelos sociales. La existencia y permanencia de una economía integrada e interdependiente (globalizada) necesita, para ofrecer garantías al proceso de acumulación del capital, que independientemente de las banderas que particularizan (cada vez menos) a los países, las reglas de juego económico sean idénticas y por lo tanto sus objetivos convergentes. 
El tema del conocimiento, en el desarrollo de la sociedad capitalista, como lo señala Gentili, es crucial a la hora de pensar en como el modelo arbitra los medios para reproducirse y por ende autoperpetuarse. Históricamente, con los medios que la tecnología de la época, la sociedad capitalista recurrió a echar mano a diferentes recursos que le permitieran difundir la base del "sentido común» necesario entre los ciudadanos que dieran legitimidad al modelo social impulsado. En este sentido, el conocimiento cobra crucial importancia como elemento de interpenetración de ideología entre los distintos grupos que conforman el mapa social.

A lo largo de la historia de vida del capitalismo, la reproducción del régimen social estuvo inextricablemente ligada al dominio y manejo discrecional de determinado conocimiento por parte de las elites gobernantes, lo que Gentili llama monopolio del conocimiento y que se define, según el autor, como uno de los elementos centrales, invariantes, en la morfología cambiante de la dinámica social. Es decir, hay aspectos que permanecen inalterables y que son funcionales a la reproducción y perpetuación de un orden social determinado. En palabras de Gentili (1994, p. 122):

El monopolio del «conocimiento» es uno de estos elementos centrales en la permanencia cambiante de la morfología del poder que caracteriza a las sociedades divididas en clases. Tal proceso ( $y$, consecuentemente, las luchas alrededor, sobre y por el conocimiento) constituye una tendencia invariante, permanente y necesaria pare la reproducción de la sociedad capitalista en cuanto tal.

El dominio de los medios de comunicación (de importancia crucial) y la transformación profunda de los anquilosados sistemas educativos de la región, constituyeron dos de las más importantes estrategias de los ideólogos neoliberales para sus objetivos de monopolizar creciente y progresivamente el discurso responsable de crear el consenso social del modelo. Tanto los medios de comunicación masiva como los sistemas educativos formales, se constituyen en poderosas herramientas de difusión e inculcación ideológica, por lo cual operan como formadores de conciencia ya que el propósito es impactar y transformar en la dinámica de las prácticas sociales, con el consecuente corpus de valores implicados. Es decir, la escuela y los medios de comunicación cumplen la función de educar en la medida en sus acciones colaboran en la construcción y difusión de una manera de concebir la realidad social.

A nadie escapa la magnitud del impacto cultural de los medios de comunicación, no quedan dudas acerca de su poder en la formación de «opinión pública»: el día a día cotidiano, el «sentido común» del ciudadano promedio, sus tendencias de conductas y hábitos determinados (el llamado perfil de consumidor por ejemplo), etc. En lo que respecta a la educación, no es ninguna novedad tampoco pretender demostrar su función de formador de conciencia, solo que, en el horizonte de este proceso de transformación económico-social, a la escuela se le asigna nuevamente una función para nada menor, y el espíritu del actual proceso de reforma se enmarca en el contexto político de la misma.

Las apreciaciones acerca de que la educación institucionalizada es una de las prácticas sociales privilegiadas para la difusión e inculcación de ideas, el docente, como actor preponderante en el proceso de transmisión del conocimiento social y culturalmente válido, es de por sí considerado un intelectual encargado en la elaboración y difusión de una determinada concepción del mundo. Su acción en este sentido, coincide con los mensajes vehiculizados a través de los medios de comunicación masiva, por lo 
tanto uno como otro operan como operadores de inculcación ideológica en la medida que contribuyen a la formación de la conciencia social, responsable de la transformación de las prácticas sociales.

El actual proceso de reforma se inscribe en el marco del contexto socio-político descrito, cuyo propósito es el reordenamiento profundo de la política educativa, para poner a tono a todo el sistema, en función de las demandas del nuevo pacto social impulsado por el modelo neoliberal. En función del mismo, los lineamientos políticos impulsados desde la Ley Federal de Educación en el tema de la formación docente, plantean como principio fundamental, la capacitación y la actualización de maestros y profesores en tanto a su dominio de los nuevos contenidos básicos comunes (C.B.C.), que prescriben los saberes y conocimientos social y culturalmente válidos, que todos los alumnos deben adquirir. Estos contenidos, elaborados por un grupo de expertos de los diversos campos del conocimiento, constituyen la garantía para que los alumnos logren las capacidades necesarias que les permitirán incorporarse al mundo social concebido por el nuevo pacto social: en lo económico, en lo político, en lo cultural.

Bajo el paraguas ideológico de las políticas neoliberales, las reformas educativas instrumentadas en la región se moldearon en la perspectiva del más puro positivismo: la escisión entre técnica y política, creando la figura del técnico especialista como profesional no contaminado de preceptos ideológicos y políticos. Esta tecnocracia a cargo de la política educativa, semejanza de cómo se operaba en los otros órdenes sociales, se constituyó en una vanguardia burocrática que avanzó sobre el derruido territorio del sistema educativo, pontificando acerca de las «nuevas verdades del mundo pedagógico de vanguardia» $y$ simultáneamente, amenazando con la inevitable la instrumentación de este tipo de reformas, se sintetiza perfectamente en una frase pronunciada por muchos apóstatas del modelo neoliberal: «Yo o el caos».

Lo evidente, de acuerdo al sucinto análisis del nuevo reordenamiento del capitalismo, es que el núcleo central de los aires reformistas responde a una visión de claro corte economicista. La política educativa queda así definida a partir de un discurso pretendidamente progresista y optimista, que echa a mano una vez más a esa visión mesiánica de aquel por sí solo basta para operar transformaciones de la práctica educativa, en la medida en que los actores (los docentes) crean en las bondades del mismo (Gimeno Sacristán, 1999); pero que en la práctica se contradice por la coyuntura del contexto político que cuestiona la esencia misma de las concepciones esgrimidas en dicho discurso.

Ejemplificando, se puede apreciar que los ejes centrales de la reforma educativa en Argentina han quedado atrapados en la tensión que se genera entre: formación política (participación formal versus participación solidaria), nuevas formas de reconocimiento salarial (por producción/por función desempeñada), formación para el trabajo (demandas del capital/formación integral polivalente), nuevos modelos institucionales (escuelas de autogestión/escuela de calidad para todos), nuevos desarrollos de la ciencia (reproduccionismo/producción del conocimiento), incorporación de nuevos valores sociales (individualismo/solidaridad), reformulación de vínculos laborales (flexibilidad, competitividad/estabilidad, solidaridad), nuevos modelos docentes (profesionalización «neutra»/práctica social comprometida). En estas tensiones se patentiza con claridad el conflicto aludido, traducido en términos de imponer-resistir la reforma. 
En síntesis, el actual proceso de reforma, tal como se plantea en la Ley Federal de Educación, implica una transformación profunda del sistema en la medida en que baja una nueva estructura del mismo y se define un nuevo ordenamiento curricular. Sobre esto, los contenidos son elaborados por los equipos técnicos convocados por el Ministerio de Cultura y Educación, que prescriben los saberes básicos del corpus curricular nacional, determinando simultáneamente los contenidos jurisdiccionales (provinciales/regionales) e incluso los institucionales. En estos contenidos están incluidos lo que el docente debe enseñar a sus alumnos, como también lo que deben enseñar los docentes encargados de formar a maestro y profesores. El pequeño detalle es que los maestros y profesores participan en calidad de sujetos pasivos en todo el proceso.

\section{IMPERATIVOS POLÍTICOS QUE FUNDAMENTAN A LAS REFORMAS EDUCATIVAS}

En otro orden, vale dejar en claro los elementos de base que fundamentan políticamente los procesos de reformas educativas de la región, obedece a tres imperativos. Un imperativo anima al movimiento reformista bajo la premisa de reducir los presupuestos del sector público en el marco de la profunda crisis que sufren los países de la región. Un segundo imperativo está intrínsecamente ligado al paradigma de la nueva economía mundial: se trata de las reformas impulsadas por la competitividad, como una estrategia de poner a la educación a la altura del proceso de mundialización; sus objetivos son básicamente incrementar el rendimiento académico de los alumnos, a los fines brindarles el aprendizaje de aquellas las competencias laborales, con el objeto de incorporarlos como capital humano de competitivo al sistema productivo que ya toma rasgos definitorios a nivel mundial. Un tercer imperativo es el que está ligado al concepto de equidad: se trata de transformar la función política de la educación como vía de movilidad social. En todas las reformas, estos tres imperativos están presentes en mayor o menos medida, pero hay que prestar especial atención a el objetivo de máxima, no siempre evidente, es, en el marco de la revolución conservadora que venimos analizando, la reducción de la inversión pública en educación. Como lo señalan Ángel Díaz Barriga y Catalina Inclán Espinosa (2001, p. 4):

Ciertamente los autores expresan que estos tres componentes de alguna manera se encuentran en las reformas, y ciertamente se puede afirmar que sí en algún sentido; sin embargo, tal como dichos autores reconocen, la mayoría de las reformas tiene como intencionalidad real, oculta en el discurso que las sustenta, la reducción del gasto educativo, aunque desde un punto de vista argumental se exprese lo contrario.

Si se piensa en la naturaleza de las nuevas prácticas sociales, concebidas a partir de la óptica economicista del modelo neoliberal en tanto a la introducción de profundas reformas que buscan «sanear» las economías fuertemente endeudadas de los países en vías de desarrollo, las políticas de formación docente se inscriben en el contexto de la redefinición de Estado. En este sentido, se produce una extrapolación de concepciones y elementos instrumentales específicos del universo económico, hacia el universo específico de la educación. Es por demás elocuente que en las resoluciones del Consejo Federal Cultura y Educación, un criterio de prevalente racionalización instrumental para direccionar los insumos y los productos de la formación profesional docente: se sistematizan, con creciente rigurosidad, a los procesos inherentes a la enseñanza y a las actividades que hacen a la dinámica de las instituciones educativas, al sólo efecto de poder medir, cuantificar y valorar la relación económica entre insumos y productos (Barco, 1999). 
Es así como el director de escuela se lo asimila al papel de gerente; la formación educativa se subordina al mundo laboral (educación para el trabajo), definido por la demanda empresarial; se prevé una creciente participación económica de la comunidad educativa en su conjunto a los efectos de sostener e impulsar políticas que apoyen la transformación de las instituciones educativas, lo que representa la tendencia del Estado a reducir paulatinamente su responsabilidad básica de garantizar económicamente los servicios educativos. Los alumnos pasan a ser categorizados como clientes, quienes de la manos de sus padres elegirán aquellas escuelas cuya oferta se ajuste mejor a sus necesidades e intereses, por ello se introduce el concepto de «competitividad» como regulador dinámico de la oferta educativa. Por ello, se piensa en nuevos modelos institucionales, concebidos a partir de nuevas relaciones intra e interinstitucionales, determinando un replanteo en cuanto a la función social de la educación. Como corolario, es obvio que se necesita una nueva función del docente para este modelo escolar empresarial, cobrando relevancia la denominada «reingeniería educativa». En suma, lo que se desprende fundamentalmente de este análisis es el replanteo de la distribución de las responsabilidades públicas (en este caso, la política educativa) que le caben al Estado y a la sociedad civil.

Es fundamental es entender la problemática en la compleja relación entre las responsabilidades del Estado en tanto actor que elabora y ejecuta las políticas públicas, en este caso referidas a la educación, las demandas de la sociedad civil en tanto actor político que gravita en la configuración de las políticas públicas aludidas y el contexto geopolítico mundial, que condiciona la relación, de acuerdo a las coyunturas históricas, entre los primeros actores. Si hoy hablamos de una sociedad globalizada, delineada por el ideario de la revolución conservadora, las cuestiones referentes a las políticas de formación docente se deben interpretar bajo ese universo pero retrotrayéndose al momento fundante del sistema educativo, para relacionar ambos procesos en cuanto a las posibles analogías en cuanto a la políticas de formación docente. En este sentido, tengamos presente lo analizado en punto donde se desarrollo los diferentes paradigmas históricos que conformaron los modelos de formación de la función.

Como ya se señaló, los documentos elaborados por el Consejo Federal de Cultura y Educación sobre las recomendaciones de las políticas de formación profesional, contienen una serie de prescripciones de alto contenido técnico, pero que nada dicen acerca de las condiciones objetivas del quehacer docente: no se consideran las condiciones materiales y culturales en que la docencia debe llevar a cabo sus actividades, teniendo en cuenta los aspectos intra e interinstitucionales, así como tampoco se tienen en cuenta las condiciones materiales de vida de los alumnos, destinatarios naturales de los propósitos de la enseñanza ejecutadas por el maestro o profesor.

La evidencia, una vez más, de que las políticas neoliberales propugnan la descentralización del gasto pero centralizan los lineamientos de la política educativa: es claro el carácter centralizador de los modelos de capacitación y actualización profesional, que soslayan las problemáticas específicas, tanto a nivel regional como a nivel institucional, configurándose en una suerte de moldes elaborados por la conducción ministerial a nivel nacional. 
Silvia Barco (1999) en un interesante trabajo en donde relaciona las implicancia políticas de la reforma educativa con los lineamientos que regulan la formación docente, enumera una serie de cuestiones que revelan el verdadero espíritu de la reforma. Vale destacar algunos de sus principales puntos que nos servirán para esclarecer aún más la naturaleza de su impacto en la formación docente:

La participación de los docentes en las resoluciones que marcan los lineamientos políticos de la reforma educativa son meramente formales y simbólicos. La participación del docente queda reducida a contestar encuestas elaboradas por los organismos oficiales.

2 La formación docente se centra en una formación de competencias profesionales, entendidas como un corpus de saberes y conocimientos específicos que el docente debe dominar. La concepción de los contenidos básicos comunes, clasificados como conceptos, procedimientos y actitudes, configura intervenciones pedagógicas que el maestro y/o el profesor pone en juego en situaciones de aprendizaje definidas por los sujetos destinatarios, en contextos institucionales específicos; en esta la enseñanza es concebida a partir de la diagnosis acerca de las capacidades propias del individuo (alumno), de la presunción acerca de que manera se podrá desempeñar en el mundo laboral, por lo cual se planifica y ejecuta aquella formación que ha de resultar como verdaderamente útil para ese individuo. La evaluación de la calidad educativa se constituye en el paradigma más claro de esta cuestión. Como bien lo plantea la autora, se trata de una «pedagogía de las competencias» cuyo propósito es prescribir un modelo educativo formador de sujetos funcionales a las nuevas condiciones laborales imperantes en la economía de mercado. Dichas competencias se regulan mediante un sistema evaluación que mide la calidad de los productos educativos.

La política de formación docente gira en torno a una concepción de profesionalización basada en la obligación del docente en la acreditación permanente de sus competencias profesionales, mediante la toma de los correspondientes cursos propuestos por el Sistema Nacional de Acreditación de la Capacitación Docente. La capacitación en cuestión se supedita a acreditaciones en base a determinados perfiles que se evalúan con pruebas nacionales, diseñadas por los organismos centralizados del Ministerio de Educación. Según Barco, esta política de formación docente no tiene en cuenta, por un lado el contexto material y cultural en el que se desarrolla la labor profesional del docente, por el otro las condiciones objetivas y simbólicas, en las que la vida de los alumnos como sujetos sociales tiene lugar, destinatarios naturales de sus acciones profesionales. Se trata simplemente de un modelo de fuerte corte meritocrático, que subordina al docente a la aprobación compulsiva de saberes y conocimientos prescritos por los «expertos», descontextualizados de la realidad social y cultural del hecho educativo. Además, en el marco paradigmático de la competencia como nodo regulador del mercado laboral, una política de profesionalización esencialmente meritocrática no persigue otro fin que limitar las ofertas de puestos de trabajo en manos de quien monopolice la mayor cantidad de acreditaciones. Además, este carácter centralizador y meritocrático, solidario en los hechos con el carácter poco democrático en la toma de decisiones, constatado en los hechos desde la implementación de la reforma educativa, convierte al docente en una suerte de rehén del Estado: podrá ejercer su labor profesional en la medida en que se somete a los lineamientos establecidos por la política de capacitación. Ampliando el concepto, en palabras de Barco (1999, p. 3): 
«....no es aventurado sostener que, además de ser un mecanismo de "reducción objetiva" de puestos de trabajo, según las posibilidades de los magros presupuestos para educación, se trata de un dispositivo de recompensas y castigos según los grados de adhesión a la propuesta estatal»

Se prescriben nuevos modelos de organización institucional, acordes a la nueva estructuración pedagógica del sistema educativo y a la redefinición de la función profesional docente, conjuntamente, con el nuevo diseño curricular concebido a partir de la decisión de los expertos, sin la participación efectiva de los protagonistas directos del hecho educativo. Se impone una visión reduccionista del mismo, circunscribiéndolo a cuestiones puramente técnicas, escamoteándole su inscripción política como práctica social. Nada se dice sobre las condiciones de profesionalización en función de la complejidad de la tarea, poniendo sobre el tapete la situación salarial del docente; nada se dice sobre las culturas institucionales de las escuelas, signadas históricamente por tradiciones que han determinado una dinámica caracterizada por rutinas bastante resistentes a los cambios; nada se dice acerca de la compleja, conflictiva y contradictoria relación entre la escuela y el contexto social donde opera el docente cotidianamente; solo se habla de gestión curricular en el marco de un modelo institucional extrapolado del universo empresarial, como las condiciones para el cambio. El docente se debe capacitar en dicho contexto y se puntualiza su esfuerzo y su compromiso en una suerte de cruzada para ubicarse en esta realidad, se desprende de todo esto que la capacitación y actualización sólo depende de él en tanto individuo que asume su responsabilidad para ponerse a la altura de las circunstancias. Nuevamente, en palabras de Barco (1999, p. 3):

La organización institucional y el currículum parecen ser condiciones necesarias y suficientes para ser profesional. El salario no. Los documentos hacen un llamamiento al profesional para que comprenda que su vida laboral es una carrera profesional, pero que, a su vez esta carrera debe ser asumida como un comprom iso personal. La profesión resulta entonces una vocación individual y la formación docente no se relaciona como política, con una propuesta de carrera docente.

2 La formación docente se reformula a partir de la premisa de la especialización por niveles, es decir, el docente focaliza su profesionalización de acuerdo al grupo etario de pertenencia de los alumnos. Así, hay docentes para el EGB 1 y 2, docentes para EGB3 y polimodal, etc. La justificación de ello se plantea a partir del criterio de optimización de los recursos humanos, dada la especificad pedagógica de cada uno de los niveles, teniendo en cuenta los perfiles evolutivos (psicopedagógicos y sociales) de los alumnos. La perspectiva curricular de la formación docente, según Barco, se estructura a partir de tres ejes. El primero está referido a la formación general, común a todos los niveles, centrada en el abordaje de la realidad institucional de la educación pero restringida a una visión formal del sistema educativo, no inscribiéndolo en un contexto que permita su significación en el campo de las prácticas sociales que se dirimen a partir del entrecruzamiento de fuerzas políticas que luchan entre sí. El segundo se centra en la caracterización del alumno, adscribiendo su significación desde la perspectiva de su inclusión en un determinado grupo etario: la psicología evolutiva y las teorías del aprendizaje brindan el andamiaje conceptual necesario para su descripción genérica, descontextualizando al alumno como sujeto social, desconociendo su adscripción como tal a un universo que le confiere cultural e históricamente si identidad. El tercer eje hace hincapié en la formación curricular específica, es decir, forma en los contenidos específicos de acuerdo al nivel, la disciplina. Sobra decir que, como trans versalizador de la formación, se pone el acento en cada uno de los ejes, en la importancia central de los CBC que configuran el nuevo diseño curricular. Se infiere una formación reducida a cuestiones puramente técnicas, circunscrita al aprendizaje de saberes especializados que, sin desmerecer su relevancia 
pedagógica, son concebidos como el ABC de la formación. La ahistoricidad y el escamoteamiento del factor sociopolítico de la educación como práctica social, consolida un imaginario docente fragmentado en representaciones epistemológicas poco apropiadas para relacionar al hecho educativo con los procesos sociales, culturales y su atravesamiento histórico y político. Es una formación profesional de carácter eminentemente instrumental, que aísla al docente del marco productor del universo pedagógico; otros, los «expertos» se encargan de seleccionar y organizar lo que él debe luego bajar al aula. Se busca una formación donde el deber ser cobra nuevos bríos bajo el ropaje del constructivismo y la calidad educativa: se pretende un pensamiento docente "adocenado», coherente con la ideología del pensamiento único que el modelo neoliberal propugna en todos los órdenes de la vida social.

Según Díaz Barriga e Inclán Espinosa (2001), este tema se plantea en términos de la tensión del docente como sujeto-ejecutor de las reformas, por lo cual las actuales que dominan buena parte de la realidad latinoamericana, no hacen más que impactar negativamente en las posibilidades de un cambio real del paradigma educativo. Es harto comprobable en la actitud de buena parte de los docentes que ellos no suelen identificarse con los fundamentos y postulados de las reformas. Funcionarios y técnicos responsables observan con creciente preocupación que los docentes no se apropian de la reforma en ciernes, asumiendo actitudes que van desde el rechazo manifiesto hasta una aparente aceptación de los postulados reformistas pero que en realidad el docente los ignora silenciosamente 0 arbitra estrategias implícitas a los efectos de sabotearlos. Es por ello que surgen una y otra vez estas preguntas: ¿Por qué los docentes no se constituyen en plenos protagonistas centrales de las reformas?, ¿por qué actúan frente a las mismas con creciente rechazo? ¿Qué razones se ven involucradas en el sostenimiento de su actitud refractaria a las propuestas de cambio que enarbolan las reformas educativas? Seguidamente se intentarán algunas posibles respuestas.

\section{SEIS CUESTIONES CRÍTICAS DEL POR QUÉ DEL FRACASO DE LAS REFORMAS}

En principio, pensemos a la actividad docente en el marco de una profesión que tiene una serie de características específicas que le confieren una identidad diferencial respecto al resto de funciones laborales; a los fines del presente análisis, señalaremos algunos elementos para entender la problemática de la reforma como obstáculo en el cambio de la cosmovisión de la educación que debería operarse en el imaginario de la docencia y por ende, traducirse en el reorientamiento de las prácticas. Según habíamos visto, la creación y configuración de los sistemas educativos modernos son el resultado del surgimiento del nuevo paradigma sociopolítico de la sociedad industrial; allí se erigen los estados nacionales como entidades reguladoras de las nuevas relaciones sociales.

Es así que, en torno a este proyecto se estructura la actividad docente que conocemos, un sujeto que recibe una preparación formal habilitante para ejercer la tarea de enseñar y es por ende contratado para realizar la misma, es decir, el docente se convierte en un agente del Estado, dotado de una misión específica. Si bien se suele señalar que el docente es un profesional cuya labor es eminentemente de corte intelectual, dotada de reglas precisas de funcionamiento, de procedimientos concretos de ingreso a la profesión, y que cuenta con un cuerpo de conocimientos propio, en un intento de homologarla con otras 
profesiones de rango intelectual, en la práctica se observa que ello no es así dado que si nos atenemos a la caracterización que hace la sociología de las profesiones, ésta señala como uno de los requisitos esenciales para que un trabajo sea considerado profesional un alto grado de autonomía en el desempeño de la tarea (A. M. Pérez, 1999).

Por lo pronto la tarea docente está ineludiblemente ligada con los proyectos del Estado que tiende a la ritualización burocrática de su quehacer, dado que, como lo señala Díaz Barriga (2001) al maestro o profesor les son dados, prescripciones precisas que regulan su desempeño: que contenidos enseñar, cumplimiento de determinados programas en un tiempo acotado, realizar las acreditaciones de los aprendizajes de sus alumnos mediante procedimientos específicos, etc., casi siempre a través de estilos institucionales de tipo autoritario; y percibiendo por todo ello un salario. Las imágenes de la docencia como agente social que cumple un determinado papel, van desde las concepciones místico-religiosas de la era comeniana, que conciben a la docencia como un apostolado, siendo el maestro un modelo moral ideal para sus alumnos (aún fuertemente presente en no pocos docentes), pasando por la visión artesanal (ya superada), llegando a las dos imágenes más fuertes que atraviesan el imaginario actual: la del docente visto como un profesional y la del docente homologado como un trabajador asalariado, un obrero de la educación pero siempre condimentado por los resabios de las concepciones comenianas. En definitiva un profesional concibe, planifica y toma decisiones, situación que no ocurre en caso del docente: las cuestiones de política educativa, como es el caso de las reformas, las resuelven los «expertos».

Las reformas educativas que han pretendido impactar en la medida de lograr un cambio del paradigma educativo vigente, han ignorado justamente esta naturaleza intrínseca del imaginario donde se nutre la actividad del docente. Siguiendo un pertinente análisis de Díaz Barriga e Inclán Espinosa (2001) y de la pedagoga argentina A. M. Pérez (1999), es necesario puntualizar seis cuestiones críticas que, al particular entender de este trabajo, implican las problemáticas fundamentales, conducentes a la visualización clara del carácter obstaculizante de las políticas reformistas en el reposicionamiento de la función docente:

Primera cuestión: los docentes, en términos generales, suelen no compartir las tesis centrales de las reformas. Una mirada a las instituciones de formación docente revela en gran medida que el pensamiento del futuro maestro o profesor se sigue alimentando a partir de ideas de marcos teóricos ligados a la modernidad; es decir, el paradigma educativo que se transmite es el que esta ligado a los valores del Estado nación y su consecuente orden social; es más, se sigue nutriendo de los conceptos fundacionales del pensamiento iluminista.

Las actuales reformas parten de otros presupuestos que responden a un orden social diferente y por ende, el paradigma educativo que se intenta bajar no encuentra elementos de empalme con el paradigma en que se siguen formando los docentes y que es el que justamente se quiere reemplazar. En este sentido, para ejemplificar esta cuestión, Díaz Barriga e Inclán Espinosa hacen hincapié en que la pedagogía moderna se funda a partir de los aportes de la filosofía, cuyo paradigma termina configurándose con los nutrientes que aporta el pensamiento sociológico; así, las principales teorías educativas que conformaron las llamadas ciencias de la educación, han trazado un derrotero muy diferente al que se plantea ahora, con 
el nuevo paradigma educativo, más ligado a la economía que resalta como uno de sus ejes centrales el tema de la formación del capital humano (Díaz Barriga; Inclán Espinosa, 2001).

En otro orden, como señala Pérez (1999), en las carreras de profesorados se observan, por un lado, la escasa permeabilidad de introducir profundas reformas en la organización curricular que permitan una reposicionamiento de la formación docente, en consonancia con los requerimientos pautados en el nuevo paradigma educativo (en este sentido sólo se han hecho cambios a nivel de planes de estudios); y, por otro, una paulatina y creciente intensificación en la exigencia académica, en tanto que se somete a maestros y profesores a una demanda de formación y actualización permanente. Lo notable es que a pesar de las exigencias crecientes y de los cambios introducidos en los planes de estudios, la cualificación constatada del personal docente en la práctica dista de lo esperado; asimismo, las oportunidades concretas de crecimiento profesional para la gran mayoría de los docentes son escasas, cuando no nulas, constatándose que las posibilidades de crecimiento profesional no se revelan semejantes a otras profesiones, en términos de lograr ascensos a puestos mejor remunerados. Todo esto dispara una creciente frustración en el colectivo docente, que se traduce, entre otras, en no poder retener a aquellos individuos mejor capacitados intelectualmente y que prefieren incorporarse a otras actividades en mejores condiciones. Así, la gran mayoría de los docentes dejan su profesión en el mismo lugar donde la iniciaron.

Segunda cuestión: negada en los hechos por los funcionarios y técnicos involucrados en los procesos de reforma, pero que muchos terminan reconociendo puertas adentro, es el tema de los bajos salarios del sector y de las condiciones laborales concomitantes. Suele asociarse este factor a la creciente devaluación profesional de la actividad docente y al progresivo decremento del rendimiento académico de los alumnos, para constituir uno de los núcleos fundamentales para entender la desmotivación de buena parte de maestros y profesores.

Asimismo, esta combinación suele abortar cualquier intento de atraer a aspirantes a docentes, distinguidos por sus sobresalientes capacidades para desempeñarse en esta compleja profesión. Si pensamos a la docencia en términos de una profesión de tipo liberal, nos encontramos que por el monto de los salarios que perciben, los docentes se acercan más al universo del obrero; si se le concibe como un técnico altamente calificado desde el discurso de las reformas, en la realidad se ve asimismo no como un profesional sino como un simple empleado que percibe en salario básico por su tarea. Esto atenta contra todo intento de reposicionarlo como un profesional. La trampa se termina de cerrar con el hecho de que uno de los objetivos de máxima que impulsan la revolución conservadora de los años 90, como ya señalé, es la reducción de la inversión pública en las áreas sociales. En palabras de Díaz Barriga e Inclán Espósito (2001, p. 9):

Todo ello aleja su cosmovisión de la de un profesional (más allá del discurso asumido en esta perspectiva, que juega más como una justificación ideológica o una racionalización) y se acerca a la de un proletario.

Más adelante agregan:

Finalmente, la reforma misma se encuentra atrapada en la necesidad del Estado de reducir el gasto social, y, a la vez, en la exigencia de impulsar una reforma que eleve la calidad de la educación, lo que entre otras cosas implicaría mejorar tanto la infraestructura escolar como las condiciones de trabajo docente. La educación, de ser una función social del Estado nacional, se convirtió en una carga fiscal, y la reforma en el instrumento para aligerar dicha carga. 
Un dato no menor es el hecho de la llamada feminización de la actividad docente. Resulta obvio que en la docencia, en particular en el nivel de educación básica (inicial y primaria), haya un predominio de mujeres; se han esgrimido diferentes causalidades explicativas, entre ellas cobra importancia la asimilar la enseñanza a la crianza de los hijos, lugar privilegiado de la mujer en la sociedad burguesa tradicional; no obstante, en tren del presente análisis del tema salarial, se ha comprobado que si la remuneración en la educación formal es baja, comparada con otras profesiones que implican exigencias laborales similares y un nivel intelectual también similar, los hombres suelen preferir desempeñarse en otras ocupaciones mejor remuneradas, quedando la actividad docente atrapada como reservorio laboral para aquellos que no cuentan con otras posibilidades laborales mejor remuneradas, en este caso las mujeres.

Por otra parte, una verdad de perogrullo pero conveniente de señalar, es el hecho de que la labor docente se ha estructurado siempre en gran medida sobre la base de dos aspectos: la carga horaria total destinada a la tarea, dentro y fuera de la escuela y el volumen de la matrícula de alumnos que integra el grupo-clase a cargo. Estos dos factores tienen decisiva gravitación cuantitativa del trabajo a realizar y en la intensidad del mismo, que obviamente impacta en la calidad de la vida laboral y en la calidad de a enseñanza dispensada por maestros y profesores (Pérez, 1999). Sobre la carga horaria que implica la tarea docente, se sabe, pero en la práctica ni los funcionarios ni los técnicos parecen incluirlo como dato fundamental a la hora de instrumentar las reformas, que las horas destinadas al trabajo áulico, reconocidas salarialmente, constituyen únicamente una parte de las horas reales de labor de la mayoría de los docentes.

Las reformas y en especial la actual han determinado una sobrecarga de tareas extras que no tienen reconocimiento alguno como trabajo efectivamente realizado y que por ende debe remunerarse. Asimismo, tampoco este cambio en las funciones ha sido acompañado por una modificación en el sistema normativo que regula al sistema educativo. A las funciones esenciales, el trabajo pedagógico concreto de la enseñanza, se agrega, en un escenario de recorte del gasto público, la necesidad de responder a una incorporación masiva de matrícula que se traduce en la práctica en un aumento del número de alumnos por aula. Simultáneamente, la dimensión administrativa de la labor docente aumenta considerablemente, llegando en no pocas ocasiones a desplazar a lo pedagógico como eje fundamentan de la tarea docente.

También, de acuerdo a los principios vertebradores del nuevo paradigma educativo, la dimensión comunitaria cobra un papel de especial gravitación, tendiente al mejoramiento de la calidad educativa, y que demanda al docente el hecho de agregar nuevos esfuerzos un su actividad, por el mismo precio: llenar planillas, contestar cuestionarios de encuestas, atender a los padres, participar en reuniones institucionales, atender la demandas específicas de una matrícula que ha observado de un creciente y progresivo deterioro social, elaborar los planes de estudio, etc. han determinado que las condiciones en que se desarrolla la tarea docente, sea vivida por éste como una carga pesada. Muchos de los males que han ido minando la satisfacción laboral de maestros y profesores se han atribuido en alguna medida a las consecuencias nefastas de la reforma: si estos elementos funcionales de las dimensiones administrativa y comunitaria se los percibe sobredimensionados en la dinámica institucional de la escuela, en el imaginario docente se los vive devaluados como actividad, pues ellos consideran que desvirtúan la sustantividad misma de su función: enseñar. 
Tercera cuestión: es la referente a la imagen social de la docencia, es decir, el espejo que la sociedad le devuelve al docente acerca de su labor. Históricamente, el docente sabía lo que se esperaba de él y, en el marco del proyecto socio-político de los estados nacionales, su labor gozaba de un prestigio social, por lo cual era respetado. Hoy por hoy, desde hace bastante tiempo, se sabe que esto ha cambiado y que el prestigio de antaño mencionado ha menguado considerablemente. Hoy ya no constituye un referente para las jóvenes generaciones y su labor se ve hoy día no pocas veces cuestionada por distintos actores sociales. Asimismo, en la naturaleza de la profesión docente se destaca, entre otras, su falta de autonomía en la toma de decisiones, por lo cual, en términos de la clasificación que propone la sociología de las profesiones, la docencia no encuadraría como profesión liberal. Es posiblemente por esta razón, entre otras, que la docencia goza de un menor prestigio (en comparación con otras profesiones semejantes) en la imagen social.

Otra problemática muy conocida, es la referente a la histórica imagen social del docente, en particular, el maestro, visto como un «apóstol». Resabio de notable vigor del normalismo pedagógico, esta imagen aborta, a la larga, cualquier intento de ubicar al maestro como un profesional. En efecto, la enseñanza se concibe como instruir más que como educar, en el sentido que el concepto adquiere dentro del nuevo paradigma que se intenta instaurar. Si bien, a lo largo del siglo XX esta concepción se ha ido debilitando por diversas circunstancias, entre ellas, la de jerarquizar la carrera del magisterio reemplazando a la escuela normal por los institutos terciarios de formación docente, aún hoy se observa en el imaginario social cierta persistencia en ver al docente como una suerte de sacerdote que cumple una sagrada misión en la sociedad.

La reforma tampoco ha incursionado eficazmente en considerar que la desarticulación del discurso cuasi-religioso que envuelve a la docencia también se revela como un serio obstáculo para reposicionar a los docentes como profesionales que demanda el nuevo paradigma educativo. En suma, la realidad concreta resultante es que hoy los docentes se ven más asimilados a la imagen de ser un proletario de la educación que comparte las mismas penurias que el resto del colectivo de los trabajadores asalariados sometidos al salvajismo del modelo neoliberal.

Cuarta cuestión: en las reformas, y especialmente en la actual, la concepción del nuevo paradigma educativo revela una ausencia de interpelar uno de los nudos centrales en toda reorientación de la enseñanza, nos referimos a lo pedagógico. Se impulsa al docente a actuar bajo un nuevo ordenamiento de los contenidos a enseñar, en la perspectiva de la formación de competencias en los alumnos, para su formación apropiada. Asimismo, en vías del mejoramiento de la calidad educativa, se redimensiona el funcionamiento pedagógico bajo el paraguas de la competitividad.

Se insiste asimismo en el aprendizaje de los alumnos, bajo la perspectiva de la moderna ciencia cognitiva que da cuenta de los procesos de aprendizaje, pero nada se dice acerca de los métodos apropiados para instrumentar las nuevas propuestas de contenidos y como ajustar lo metodológico a estos perfiles psicopedagógicos. La ausencia de la pedagógico cobra mayor dramatismo a la hora de observar la contradicción entre los postulados de la reforma que concibe al aprendizaje como un proceso y el hecho de introducir una concepción netamente positivista a la hora de evaluar resultados; es decir, se hace alusión a 
los mentados procesos de medición de la calidad educativa, que se apoyan en la determinación de estándares que reflejen la eficiencia de la acción educativa. En ese ínterin, los docentes no encuentran el camino de poner en práctica lo que se prescribe, ya que no se pone en discusión las condiciones complejas y contradictorias que definen al acto pedagógico para instrumentarlo.

Quinta cuestión: es que las reformas aplican las nuevas ideas a un contexto escolar que no se adecua para ello, es decir, se instrumentan proyectos educativos basados en sus lineamientos, que deben amoldarse a la misma dinámica escolar del paradigma que se intenta reemplazar; con ello se abortan las posibilidades reales de que el cambio perseguido sea tal. No se puede pasar por alto que el viejo paradigma necesitaba de una cultura institucional delineada a partir del establecimiento de rutinas y rituales bastante rígidos.

Todo proceso de reforma, además de la instrumentación de una nueva organización del sistema, de la reconversión docente (más allá de los cuestionamientos), de la elaboración del diseño curricular y los correspondientes documentos de apoyo, de elaborar nuevos libros de texto, etc., requiere la adecuación del espacio institucional en términos organizacionales, que se configure las estructuras del mismo de acuerdo a las necesidades propositivas de lo cambios que se intentan ejecutar. Nada de ello ha pasado, ya que las reformas suelen también pasar por alto este dato fundamental.

Sexta y última cuestión: central a los fines del presente trabajo, es lo referente a las representaciones sociales típica de los docentes, a partir de las cuales ellos organizan y estructuran la vivencia y percepción que tienen de la profesión, en la perspectiva de constituirse como factores condicionantes de la propia actuación, es decir, nos adentramos en uno de los núcleos fundamentales de la problemática: la identidad del rol. Como lo señala Pérez (1999) la desorientación que reina en cuanto al perfil profesional docente y la devaluación social y salarial ha llevado a maestros y profesores a asumir una actitud rayana con la desesperación, que se traduce en la conflictividad creciente de la dinámica institucional, merma en la calidad de la enseñanza impartida, en la explosión frecuente y creciente de conflictos gremiales, etc.

Este cóctel explosivo revela lo profundo de la crisis que atraviesa al universo docente, fundamentalmente ligado a la pérdida de valoración material y social que ninguna reforma como la actual puede pasar por alto a la hora de pretender, pomposamente, en un cambio de paradigma.

Otra problemática, en el plano de las representaciones sociales, cuando se señaló la feminización de la docencia como una variable sustantiva a tener en cuenta, es que en el colectivo de maestros predomina el sexo femenino, con una tendencia de los mismos a definirse con base en los caracteres más estereotipados del perfil prototípico femenino, esto es, como lo puntualiza A. M. Pérez (1999): «una persona displicente de sociabilidad, amable, buena por sobre todas las cosas, solidaria, moderada, pacífica, contrapuesta a características tales como tomar decisiones autónomamente, más propia del colectivo masculino. No obstante, es importante destacar que no pocas veces no se observan diferencias en el desempeño docente, sea el maestro hombre o mujer; dado que justamente, la docencia, independiente del sexo de quién la ejerza, se asimila al perfil de estereotipos femenino aludido». 
Una vez más, se evidencian los resabios, ciertamente gravitantes, de los valores basales del normalismo pedagógico. Muchos docentes, ante situaciones conflictivas que enfrentan en el día a día escolar, se refugian bajo el paraguas de la docencia concebida como una «vocación sublime» o bien «un proceso recíproco de dar y recibir el amor de los niños» (A. M. Pérez, 1999). Asimismo, definen a sus alumnos construyendo una imagen idealizada de la niñez, donde predominan los componentes afectivos. Sobre este último aspecto, las maestras en especial tienden a asociar su tarea con dar afecto y protección a sus alumnos por sobre todas las cosas; suelen asumir una actitud maternal, de protección, sustentada en el presupuesto del que el niño es un carenciado (independientemente de la condición social y económica) por deficiencias de su contexto familiar. Es así como en la actividad pedagógica del maestro, llegan a tener mayor peso las cuestiones ligadas con la socialización que con el desarrollo intelectual y del pensamiento. La realidad cotidiana del aula estalla esta imagen: los alumnos responden más a la diversidad de su entorno familiar social y cultural que al pretendido docente universal.

Otra problemática vinculante es la imagen asociada a la desvalorización de la función pedagógica específica, en la que los docentes se ven a sí mismos abrumados por las demandas de tareas asistenciales frente al aumento de las carencias de los alumnos, en particular de aquellos provenientes de los sectores más castigados por las políticas del ajuste perpetuo impuesto por el neoliberalismo. El agobio que esto significa ha determinado la construcción de la imagen del docente como una suerte de institutriz, niñera, que hace de todo menos lo específico: enseñar. No obstante, aunque es patente la demanda social de sus alumnos, esta queja se contrapone con la imagen del maestro maternal y protector: esta imagen de alguna manera fertiliza el terreno para el surgimiento de la imagen maestro-niñera. De todas maneras, el asistencialismo creciente que se viene apoderando de la institución escolar obstaculiza cualquier intento de introducir sustanciales transformación a las relaciones pedagógicas: el aprendizaje deja de ser el principal el objetivo y pasa ser sustituido por funciones de contención social.

Siguiendo con listado de problemáticas dentro de la sexta cuestión en estudio, aparece aquella ligada al carácter del docente como agente-empleado del Estado y no como profesional dotado de autonomía intelectual para tomar decisiones, es la imagen de verse a sí mismo como un engranaje más de la burocracia estatal, sin poder poner en juego creativamente sus propias ideas; el vínculo laboral del docente con el sistema educativo, le devuelve una imagen, desvalorizante en definitiva, que lo posiciona como un simple ejecutor de las prescripciones decididas unilateralmente en la punta de la pirámide de la burocracia y que son a su vez controladas en su instrumentación por procedimientos más o menos estrictos.

Pedirle a un docente que fervorosamente se «ponga la camiseta del cambio» suena como una ironía si la imagen se nutre de aspectos desvalorizantes de la capacidad del docente como un sujeto activo, creador, capaz de tomar decisiones adecuadas; en definitiva, es poco probable que un colectivo profesional pueda abrazar y comprometerse en una transformación profunda si su identidad como tal es otorgada por un sistema que los concibe como empleados obedientes y sumisos, sin iniciativa propia, con las connotaciones que tal situación facilita: resignación, destino fatalista, etc. 
Una última problemática es la imagen que los docentes tienen de las autoridades: sobre los directivos de las instituciones escolares, las percepciones van desde valoraciones positivas, ligadas a considerar al director como un líder paternalista, pasando por valoraciones de la autoridad como un líder democrático (tendencia escasamente observada en las instituciones educativas) y llegando a las valoraciones negativas (con bastante predominancia hoy día) que destacan su papel eminentemente burocrático, alejado de la realidad de aula, poco capacitado para conducir a las instituciones educativas, etc. Con relación a las autoridades de los niveles jerárquicas đel sistema, la imagen que devuelven es de burócratas absolutamente alejados de la realidad escolar, tecnócratas que diseñan y planifican en abstracto, sin contacto con la cotidianeidad áulica, con poca o ninguna voluntad de transformar un sistema educativo anquilosado.

Dadas las razones precedentes, se infiere que maestros y profesores no se identifican con los fundamentos que sustentan la actual reforma educativa (y que por lo general a ninguna reforma en particular); por lo tanto, es imposible pretender que estos actores actúen en función de los lineamientos educativos pretendidos. No está demás decir que cualquier reforma, como acción concreta de una política educativa, es un proyecto cuyos resultados se perciben como propios en la medida en que garantice que los docentes sean parte decisoria de dicha política. Resumiendo el precedente análisis, resulta pertinente citar la reseña de Pérez (1999, p. 10):

De nuestro intento de reseñar la situación docente, tanto desde una perspectiva objetiva como subjetiva, conviene retener algunos aspectos, que consideramos sustanciales.

En relación con las condiciones de trabajo:

es rigidez de los sistemas educativos y de la organización escolar;

es inestabilidad de las políticas educativas;

es sobrecarga de trabajo;

aumento de responsabilidades sin aumento de autoridad;

\& congelación de los salarios en relación con otras profesiones con igual o menor nivel de calificación;

es uniformidad de los salarios, sin remunerar la calidad del trabajo;

es falta de posibilidades de hacer carrera;

deterioro de los edificios, instalaciones y equipamiento escolar; y

es tiempo insuficiente para las actividades extra-escolares.

En relación con la dimensión subjetiva del trabajo docente:

es altos niveles de insatisfacción con respecto a sí mismo y su papel ocupacional;

\& mención, para autodefinirse, de los arquetipos habituales en la literatura especializada, esto es: apóstol de la educación; técnico de la educación;

es relevancia de la cuestión del reconocimiento social como parámetro para autocalificarse, presentando una imagen de maestro no contemplada como arquetipo pedagógico: el docente marginado, desvalorizado; \&s prioridad de lo formativo - afectivo sobre lo pedagógico- instruccional;

escasa autonomía en el desempeño de la función que conlleva a una disminución de la autoestima; y

\& distancia social y empática entre las funciones de conducción y las funciones docentes.

Al mismo tiempo, y a partir de los cambios planteados por la reforma educativa, se espera por parte de los maestros:

? autonomía de decisión, elaboración y ejecución del proyecto curricular a partir del trabajo sistemático en equipo con los demás compañeros;

? atención especial a la integración de la diversidad de los alumnos en un proyecto de educación comprensiva que atienda las necesidades individuales;

? preocupación por desarrollar una cultura de la autoevaluación y de la evaluación tanto del funcionamiento del propio centro, como de su propio trabajo;

? flexibilidad e interés junto con los conocimientos técnicos esenciales, que le permitan la evaluación del entorno social y escolar y su adaptación al mismo; y

? atención a las propuestas de participación de los alumnos en el conjunto de las actividades escolares y en las de programación, evaluación y organización (Viñas Cirera 1992). 


\section{CONCLUSIÓN}

Resulta evidente que los procesos de reformas, amén de la matriz ideológica donde han sido forjados, voluntaria e involuntariamente, se desentienden de cuestiones que van desde las condiciones laborales del trabajo docente a la cultura profesional de los agentes, minando seriamente las posibilidades reales de cambio que se proponen. El tinte positivista, una vez más, conduce los aires reformistas por andariveles reduccionistas que impiden visualizar en toda su dimensión la naturaleza de la problemática que entraña el docente, su formación, su cultura profesional, sus condiciones de trabajo, etc. Las viejas imágenes arquetípicas de la docencia, lejos de capitular, mantienen su vigencia, camufladas bajo otros ropajes; el docente, cuyo imaginario ha sido forjado bajos los valores iluministas del modernismo y frente al estallido de su horizonte laboral que se contradice con el discurso reformista, no hace más que refugiarse en el viejo ideario.

Por ello, urge hoy más que nunca desconstruir los mitos y argumentos falaces históricos, que neutralizaron en el universo simbólico de la docencia, su atravesamiento político y social. La toma de conciencia, a través de la desnaturalización de actitudes y hábitos arraigados en los docentes, resulta imprescindible para cualquier propósito de innovación pedagógica que pretenda un cambio real en las prácticas educativas, contextualizadas a la luz del crucial momento histórico-social que la Argentina y toda la región latinoamericana está viviendo.

\section{REFERENCIAS BIBLIOGRÁFICAS}

BARCO, Silvia Noemí (1999): Reforma educativa y políticas de formación docente en la república argentina. Ponencia presentada en el I Congreso Nacional de Investigación Educativa, Universidad Nacional del Comahue.

<http://infozeus.com/unc/COMISION2/Reforma_Educativa -Politicas_de_Formacion.doc>

BIANCHETTI, R. G. (1999): Una aproximación al análisis de las orientaciones políticas para la formación docente en el contexto de políticas de ajuste o de cómo se aplica el principio de la «bomba de neutrones" en educación. Revista HEURESIS, 1999. Vol.2, n.․ 4.

BOURDIEU, P., y PASSERON, J. C. (1998) : La reproducción: elementos para una teoría del sistema de enseñanza. México, Distribuciones Fontamara.

BRASLAVSKY, Cecilia, y COSSE, Gustavo (1997): Las actuales reformas educativas en américa latina: cuatro actores, tres lógicas y ocho tensiones. Programa de Promoción de la Reforma Educativa en América Latina y el Caribe. <http://www.thedialogue.org/preal5.html>

DíAZ BARRIGA, Angel, y INCLÁN ESPINOSA, Catalina (2001): «El docente en las reformas educativas: sujeto o ejecutor de proyectos ajenos», en: Revista Iberoamericana de Educación, 26. Madrid, OEI.

GALLEGO, Alejandro Álvarez (2001): «Del Estado docente a la sociedad educadora: ¿un cambio de época?», en: Revista Iberoamericana de Educación, 26. Madrid, OEI.

GAVILÁN, Mirta Graciela (1999): «La desvalorización del rol docente», en: Revista Iberoamericana de Educación, 19. Madrid, OEI.

GENTIL, Pablo (1994): Proyecto neoconservador y crisis educativa. Buenos Aires, Centro Editor de América Latina.

GIMENO SACRISTÁN, José (1999): «Políticas y prácticas culturales en las escuelas: los abismos de la etapa postmoderna», en: Revista Electrónica Heuresis, volumen 2, año 1999. <http://www2.uca.es/HEURESIS/heuresis99/v2n1.html (julio de 2000)>

GIMENO SACRISTÁN, José, y PÉREZ GÓMEZ, Ángel (1992): Comprender y transformar la enseñanza. Madrid, Ediciones Morata.

HARGREAVES, Andy (1994): Profesorado, cultura y posmodernidad. Madrid, Ediciones Morata.

PÉREZ, Ana María (1999): Los maestros y la reforma educativa. <http://www.iacd.oas.org/La\%20Educa\%20121/perez.htm>

PUIGROSS, Adriana (1990): Sujetos, política y currículum en los orígenes del sistema educativo argentino. Buenos Aires, Editorial Galerna.

ZACCAGNINI, Mario (2002): «El crepúsculo de los imaginarios pedagógicos», en: Revista Novedades Educativas, Año 13, № 133. Buenos Aires. 


\title{
Contactar
}

Revista lberoamericana de Educación

\author{
Principal OEI
}

